\title{
Resilient manufacturing
}

\author{
Andrew Kusiak ${ }^{1}$ (]
}

Published online: 17 December 2019

(c) Springer Science+Business Media, LLC, part of Springer Nature 2019
The market and industry face a customer-assertiveness and manufacturing-uncertainty dilemma. While customers expect product personalization and on-time delivery, the manufacturing industry is affected by uncertainty of different origins. Products and companies are impacted by the natural and human-made disruptions ranging from materials, components, and energy shortages to inconsistencies in supply chains and operations of physical and cloud assets. Assessing vulnerability of an enterprise to the unexpected disruptions and mitigating their impact leads to manufacturing resiliency. Resiliency is usually defined the ability of system to recover from an undesired state and to a desired state. Global issues such climate change and pollution, have generated interest in resiliency of infrastructure, transportation, energy, and water. Manufacturing as a base of economic activity deserves a comprehensive approach to understanding and modeling resiliency. It is not enough to think that shortage of materials and comments or natural disasters (e.g., earthquakes) are the only factors impacting resiliency, rather detailed analysis of all existing and emerging inputs to manufacturing is needed.

A list of resiliency attributes and their impact on manufacturing is provided in Kusiak (2019). They include energy, materials, components, physical assets and processes, transport, supply chain, communications, logistics, efficiency, productivity, capacity, dependability, quality, compatibility, sustainability, workforce, and societal values. Though some of these attributes may seem distant from the manufacturing resiliency equation, a closer analysis may prove a valid relationship. These attributes are expressed in variables, some of which are measurable. Identification and definition of these variables is important to unravelling the full nature of manufacturing resiliency.

The variables impacting manufacturing resiliency are evolving at different time and spatial scales. This changing manufacturing environment brings predictive science into the resiliency domain. Deep and broad learning (Kusiak 2020) quite naturally become candidate predictive technologies to address the data generation, analysis, and autonomy of the manufacturing residency solutions.

\section{References}

Kusiak, A. (2019). Fundamentals of smart manufacturing: A multithread perspective. IFAC Annual Reviews in Control, 47, 214-220.

Kusiak, A. (2020). Convolutional and generative adversarial neural networks in manufacturing. International Journal of Production Research. https://doi.org/10.1080/00207543.2019.1662133.

Publisher's Note Springer Nature remains neutral with regard to jurisdictional claims in published maps and institutional affiliations.

Andrew Kusiak

andrew-kusiak@uiowa.edu

https://research.engineering.uiowa.edu/kusiak/

1 Department of Industrial and Systems Engineering, The

University of Iowa, 4627 Seamans Center, Iowa City,

IA 52242-1527, USA 